\title{
Rare Neoplastic Syndrome
}

National Cancer Institute

\section{Source}

National Cancer Institute. Rare Neoplastic Syndrome. NCI Thesaurus. Code C35561.

A broad classification for uncommon disorders in which the development of neoplasms occur in association with a characteristic set of signs or symptoms. These disorders commonly have a genetic basis. The types of neoplasms themselves are not necessarily uncommon. 